\title{
Who Should Intervene?
}

\author{
Fredrik D. Hjorthen ${ }^{1}$
}

(C) The Author(s) 2017. This article is an open access publication

\begin{abstract}
The objective of this paper is to develop a novel account of how the duty to undertake humanitarian intervention should be assigned to states. It takes as its point of departure two worries about the best existing answer to this question, namely: (a) that it is insensitive to historical considerations, and (b) that its distribution is unfair. Against this background I propose that the duty to intervene should be assigned to states based on the strength of their claim to reject the burden of intervention. Specifically, I argue that the strength of such claims should be determined by ability to intervene effectively, adjusted for historical responsibility for the rights-violations taking place, and the extent to which their capacity for intervention derives from resources tainted by historical rights-violations. This approach, I will argue, can better accommodate the centrality of protecting the victims while also taking into account both historical and distributive concerns.
\end{abstract}

Keywords Humanitarian intervention · Duty to intervene · International justice $\cdot$ Historical responsibility $\cdot$ Disgorgement

Fredrik D. Hjorthen

fredrik.dybfest.hjorthen@gu.se

1 Department of Political Science, University of Gothenburg, Box 711, 40530 Göteborg, Sweden 


\section{Introduction}

Many theorists have argued that there is a moral duty to intervene militarily in order to halt or prevent egregious violations of basic human rights. ${ }^{1}$ Far less attention has been devoted to the question of how this duty should be assigned to particular agents. I shall refer to this question as the 'duty specification question', and the objective of this article is to examine how it should be answered.

Answering this question is important for two main reasons: first, there is the practical point that dispersed duties tend to invite inaction (Miller 2001, p. 469; Pattison 2010, p. 4). Other things being equal, a more specific assignment of duties should therefore facilitate more effective action. The second point is more principled. It seems plausible that some agents have a stronger duty to intervene than others, and that some might have none at all. If genocide breaks out in Mali we find it intuitive that France has a stronger duty to intervene than Nepal. A more specific assignment of duties allows us to take this into account.

In this article I will argue that the duty to intervene should be specified among states based on what I call the history-sensitive ability account. ${ }^{2}$ I will take as a point of departure James Pattison's Moderate Instrumentalist Approach, since this is the most developed and plausible duty specification account in the literature. My overall strategy will be to keep what seems right about this account-a strong emphasis on effectiveness-while avoiding its weaknesses. I argue that the main weaknesses of Pattison's account are that it disregards historical responsibility and distributive fairness among potential interveners. In opposition to this, I will argue that the duty to intervene should be assigned to states based on the strength of their claims to reject the burdens of intervention, where such claims should be determined by a combination of ability to intervene effectively, historical responsibility for the rights-violations taking place, and the extent to which their ability to intervene derives from resources tainted by historical rights-violations. This approach, I will argue, can better accommodate the centrality of protecting the victims while also taking into account both historical and distributive concerns.

\footnotetext{
1 See e.g. Bagnoli (2006), Caney (2005b), Fabre (2012), Pattison (2010, 2013), Tan (2006), Tesón (2005). For the sake of argument, I will assume that the conditions necessary for making military humanitarian intervention morally permissible can be met. Regarding the appropriate threshold for intervention, the reference to 'egregious violations of basic human rights' is meant to capture both a gravity condition and a numbers condition (Pattison 2010, p. 23). This includes, but is not necessarily limited to, mass atrocity crimes such as genocide, war crimes and crimes against humanity. For discussion of the issue of permissibility and the threshold for intervention, see e.g. Caney (2005b), Fabre (2012), McMahan (2010), Tesón (2014). Finally, although I do not frame the argument in terms of the Responsibility to Protect (R2P), the arguments I develop in this article should also be of relevance for some of the responsibilities central to this concept. For an overview of the R2P, see e.g. Evans (2008).

${ }^{2}$ I will refer to states as the bearers of the duty to intervene. Two reasons justify this assumption. First, states are, in practical terms, the most relevant agents for acting on the duty to intervene. Second, states can in this context usefully be seen as proxies for the duty-bearing individuals from whom they are made up. The focus on states is instrumental, and is consistent with the individualist view of the proper sites of rights and duties according to which the duty to protect human rights ultimately attaches to individuals. For reasons of space I cannot elaborate on this view, but it is worth noting that it draws inspiration from Allen Buchanan's ‘state-as-the-instrument-for-justice view’ (1999, pp. 82-87).
} 
The paper is structured as follows: in the next section I briefly describe the main points of Pattison's view, and spell out what I take to be two central worries. I then present my own account in four stages: first, I present the general structure of the account. I then move on to examine the factors that should weigh on states' claims not to intervene. This is followed by a discussion of how these factors should be combined, before explaining how they can be employed in a way that takes into account distributive fairness among the potential interveners. Finally, I defend the account against objections.

\section{Pattison's Moderate Instrumentalist Approach}

As regards how the duty specification question should be answered, there can be little doubt that Pattison's work is the best and most comprehensive to date. ${ }^{3}$ Pattison's (2010) position is that the duty to intervene should be assigned to particular agents using what he calls the Moderate Instrumentalist Approach. ${ }^{4}$ Based on a broadly, though not exclusively, consequentialist framework, this approach suggests moral legitimacy as the factor determining who should intervene. ${ }^{5}$ The legitimacy of an agent is scalar, and can be expressed as an index where effectiveness - that is, whether an agent can be expected to be successful in undertaking the intervention, measured in terms of protection of basic human rights - is the most important factor. In addition to effectiveness, two noninstrumental factors contribute to an agent's legitimacy. First, representativeness'whether the intervener is representative of the opinions, firstly, of its citizens and, secondly, of those in the political community in which it intervenes' (2010, p. 147). Second, expected fidelity to jus in bello-that is, to principles governing just conduct in war. ${ }^{6}$ For an agent to be fully legitimate, all three factors must be fully satisfied.

While both representativeness and fidelity to jus in bello contribute to the overall legitimacy of an agent, Pattison stresses that '[...] an intervener's effectiveness is the primary, and a necessary, determinant of its legitimacy' (2010, p. 79). The most important part of being effective, he argues, is that the intervener can be expected to

\footnotetext{
3 Others, such as Caney (2005b, pp. 250-251), Fabre (2012, pp. 189-191), Miller (2011) and Tan (2006, pp. 97-106), have also discussed the duty specification question, albeit much more briefly.

${ }^{4}$ Pattison builds his argument against the background of a general, unassigned duty to intervene, or what he calls the General Duty Approach (2010, pp. 15-20).

5 Pattison follows Buchanan (2000, p. 73) in saying that legitimacy is 'about the conditions that must be satisfied if it is to be morally justifiable to use force to secure compliance with principles of justice'. Moreover, it pertains to agents in the sense of being an 'agent-justifiability question' (Pattison 2010, p. 31). Thus, legitimacy is for Pattison not about sociological or legal legitimacy.

${ }^{6}$ I will not discuss Pattison's inclusion of the rules of jus in bello as part of the account of how the duty to intervene should be assigned, beyond noting that I think it can be brought into the criterion of effectiveness. Hence, to be effective involves (among other things) acting on the duty in a permissible way, which is partly determined by expected fidelity to jus in bello.
} 
succeed in protecting the basic human rights of those it is trying to save. ${ }^{7}$ The normative conclusion that Pattison draws is that while '[...] any intervener that possesses an adequate degree of legitimacy according to this account will have the right to intervene [...] it is the most legitimate agent that has the duty to intervene' (2010, p. 12 [italics in original]).

Pattison's account has strong prima facie plausibility, but it is also subject to a set of worries. A general worry is that it is not sufficiently sensitive to the fact that humanitarian intervention consists of different types of burdens, which in turn may motivate different duty ascriptions. For example, there is no guarantee that the duties to perform and to pay for the intervention follow the same logic. ${ }^{8}$ Here, however, I will focus on two worries that have a particular impact on how the duty to perform humanitarian intervention is assigned.

The first worry is that Pattison's account is insensitive to historical considerations. ${ }^{9}$ This is by design. As he puts it:

When using the potentially blunt tool of military force to end the mass violation of basic human rights, what matters most is that the intervention tackles this violation. In the context of large-scale human suffering, an intervener's making up for past misdeeds [...] seems to be far less important. (2011, p. 217)

Pattison's point is not without appeal. It does not follow from a state being historically responsible that it would also be an effective intervener, and given the obvious importance of effectiveness, initial scepticism towards giving much attention to factors such as historical responsibility appears warranted. However, even if historical responsibility can be outweighed by effectiveness, this does not mean that it should have no weight at all. Indeed, a strong case can be made for awarding at least some role to historical responsibility. For example, in a case where states A and B can be expected to be equally effective, but where A is historically responsible for the atrocities taking place, it seems right that $\mathrm{A}$ has a stronger duty to intervene. The fact that Pattison's account does not provide any tools for assigning a larger share of the burden to A is counterintuitive. We generally find it appropriate that 'those that create the mess should clear it up'.

The second worry concerns the distributive implications of assigning the duty to the most legitimate state only. Imagine that we could determine a legitimacy score from 0-100 based on Pattison's criteria. Imagine further that state A has a

\footnotetext{
7 Pattison refers to this requirement as local external effectiveness. His overall account of effectiveness also includes global external effectiveness (protection of basic human rights for those people that are not citizens of the target community or of the intervening agent) and internal effectiveness (protection of basic human rights for the citizens of the intervening agent). Pattison is not explicit about the relative weights of these forms of effectiveness, but notes that 'The importance of global external effectiveness and internal effectiveness are perhaps best seen in a negative sense' (2010, p. 79). This seems to mean that the intervention should not harm the rights of people covered by these categories.

${ }^{8}$ For discussion of how the duty to bear the economic burden of humanitarian intervention should be distributed among states, see e.g. (Fabre 2012, p. 191; Hjorthen 2017).

9 It could be argued that the criterion of representativeness is sensitive to history, albeit indirectly, through people's opinions about the intervention and the intervener. However, this is not a point that Pattison makes.
} 
legitimacy score of $80, \mathrm{~B}$ a score of $79, \mathrm{C}$ a score of $78, \mathrm{D}$ a score of 77 and $\mathrm{E}$ a score of 76. In this case, the Moderate Instrumentalist Approach would point to A alone as having the duty to intervene. But this means that B, C, D and $\mathrm{E}$ will be let 'off the hook' entirely despite being nearly as legitimate, and it does not seem fair to require that $\mathrm{A}$ should shoulder the burden in its entirety when there are other agents at an almost similar level that could also contribute. ${ }^{10}$ This point becomes even stronger once we take into account the fact that engaging in humanitarian intervention often involves considerable danger for the intervening agent. Strong arguments are needed as to why A alone should expose itself to this danger.

Pattison suggests that this worry can be met by assigning to other states other duties associated with the responsibility to prevent human suffering that are equally demanding. Moreover, he notes that the most legitimate state is likely to vary from case to case, and that they will often be rich, Western states. This reduces the charge of unfairness, he argues (2010, pp. 197-198; 2015, pp. 200-201). However, it is not obvious that the most legitimate state will vary from case to case, and even if the assumption holds it would likely take several generations to achieve an outcome that is diachronically fair. Moreover, while it is clearly true that the unfairness can be mitigated by assigning non-intervention duties to other states, it is not obvious that Pattison can help himself to the assumption that such duties (he mentions funding the intervention and providing equipment) would be equally demanding. The performance of humanitarian intervention entails particularly serious burdens (e.g. loss of life and limb) that are not straightforwardly offset against other burdens. ${ }^{11}$ Hence, Pattison does not provide sufficient reason for leaving distributive fairness out of the equation when dealing with the question of who should perform the intervention. If we think that distributive fairness is important, which Pattison clearly does, surely we should also take fairness into account when assigning the duty to intervene.

These worries suggest that (1) it is questionable whether Pattison's approach adopts the right criteria, and (2) that the idea of picking the most legitimate state is unfair and therefore mistaken. What, then, should guide our thinking when it comes to who should intervene? The objective for the rest of this article is to present an alternative account that takes into consideration historical responsibility and distributive fairness, while retaining the importance of effectiveness.

\footnotetext{
${ }^{10}$ In order to avoid a chain of indifference there should presumably be a threshold to define the minimum level of legitimacy an agent must have in order to qualify as a potential intervener. This is in line with Pattison's (2010, p. 12) argument that only agents that have a sufficient level of legitimacy can permissibly intervene. It is probably true that the threshold will always be arbitrary to some extent.

11 For reasons of space, I cannot discuss how these burdens should be distributed among individual soldiers beyond noting that it matters whether the intervening state makes use of conscripts or volunteers. For discussion of this important issue, see e.g. (Baer 2011; Fabre 2012, pp. 185-186; Gross 2008).
} 


\section{The History-Sensitive Ability-Account}

Before presenting the details of my account, a few words are in order about its structure. Like Pattison, my objective is to find the most appropriate way of assigning the duty to intervene, not to see how the duty is generated. My goal is to explore what a just distribution of the burden of intervention should look like, given a strong presumption that humanitarian intervention is sometimes required. Assigning the duty to intervene is about assigning remedial responsibility. To be remedially responsible means 'to have a special responsibility, either individually or along with others, to remedy the position of the deprived or suffering people, one that is not equally shared with all agents; and to be liable to sanction (blame, punishment, etc.) if the responsibility is not discharged' (Miller 2007, pp. 98-99).

My strategy for assigning the remedial responsibility to intervene will be to explore factors that may weigh on states' claims to reject the burden of intervention, or what we may call non-rejectability. ${ }^{12}$ What it aims to do is to assign the remedial duty to alleviate harm based on the strength of states' claims to reject the burden; the weaker the claims to reject the burden, the stronger the duty to intervene. I shall call my account the history-sensitive ability-account.

States may attempt to reject the burden of intervention on several different grounds. For instance, a state might object that intervening would be too burdensome; that it would not be able to make a positive contribution; that it has no relevant connection to the plight of the victims; that it has a legitimate claim to its own resources and that it can therefore choose to employ them as it sees fit; or that intervening would unfairly burden the state in comparison to others. By way of example, Barack Obama made it clear in connection with the 2011 intervention in Libya that 'The burden of action should not be America's alone' (quoted in Vik 2015, p. 127).

In the following sections I will explore factors that may be used to undermine such claims: ability to intervene, historical responsibility and historical taint. ${ }^{13}$ Against the background of a general duty to intervene, the work done by these criteria is to adjust the force of the duty falling on particular states by undermining their arguments for rejecting the burden of intervention. Having examined the merits of these factors, I turn to explaining how they should be combined, and how the account accommodates distributive fairness among the potential duty bearers.

\footnotetext{
12 This means that my approach differs from that of Pattison (2010, p. 31), whose focus is on finding the agent that is most morally justified in carrying out the intervention. The structure of my argument is inspired by (Caney 2006, pp. 477-478; Duus-Otterström 2014, pp. 459-461; Goodin 2013; Haydar 2009, p. 129).

13 A further factor thought by some to give rise to remedial responsibility in the case of humanitarian intervention, is communal bonds (Miller 2011, pp. 462-463). On this view, historical, religious and/or cultural ties may give rise to remedial responsibilities. But not all forms of relationships involve special obligations, and one might even deny that relationships in themselves can generate such obligations (cf. Scheffler 1997). However, it seems that for relationships to entail special obligations they must at least fulfil some kind of intensity condition, and it seems at least uncertain that this condition is met in the case of humanitarian intervention (Pattison 2010, p. 193). Thus, even if we accept that communal bonds or relationships can sometimes generate special obligations, communal ties would have limited applicability in the case of humanitarian intervention.
} 


\section{Ability to Intervene}

Given that the objective of humanitarian intervention is to protect people from becoming victims of egregious violations of basic human rights, it is appropriate to start with states' ability to intervene. As Pattison rightly notes: 'it is of the utmost importance that the humanitarian crisis is effectively tackled, given that it involves such a high degree of severe human suffering' (2010, p. 75). Ability (and similar concepts such as effectiveness and capacity) has been discussed both as a factor for assigning remedial responsibility in general (Miller 2001, 2007) as well as in the context of humanitarian intervention (Fabre 2012, p. 191; Pattison 2010; Tan 2006, pp. 99-102). Having the ability to intervene undermines states' claims not to contribute simply because such states are those that can hope to achieve the most good. The idea is captured by the following principle:

Ability to intervene: If a state (or set of states) has the ability to intervene, then that state (or set of states) has a weaker claim to reject the burden of intervention.

To say that a state A is 'able to intervene' is to say that, were A to try and not give up, A would tend to succeed in intervening (cf. Estlund 2011, p. 212). But what is meant by 'intervening' must be explained. One might think of intervening in terms of performing the entire intervention, but that would commit us to a view whereby a state that lacks the ability to perform the entire intervention but can nevertheless make a significant contribution as a coalition member would lack the ability to intervene. This is clearly unreasonable. Instead, 'intervening' should refer to 'making a contribution' to the intervention. In line with this we can say that A's ability is greater, the greater the contribution A would make to the realisation of the goal, were A to try and not give up.

A state's ability is mainly determined by the amount and quality of the military and non-military resources it can employ in a way that is consistent with the objective of protecting the victims in a particular case. ${ }^{14}$ It matters little that a state is able to do aerial surveillance if what is needed is to put troops on the ground. Despite this, applying the principle of Ability should be quite straightforward in the context of humanitarian intervention. There is ample empirical research on what makes interventions succeed in general that can help us identify the most able states in each case (see e.g. Gizelis and Kosek 2005; Krain 2005; Seybolt 2007). Data on states' military and non-military resources is needed to do this, but this data is readily available.

However, it might seem that the application of ability is complicated by the issue of costs. As Miller notes, '[...] the capacity principle seems to blend together two different factors which may not always point in the same direction. One has to do with the effectiveness of different agents in remedying the situation; the other has to

\footnotetext{
14 Ability also depends on factors such as whether the intervener has the support of the local population (see e.g. Gizelis and Kosek 2005). Moreover, it matters what other agents are doing, as well as who those agents are. For example, while it will often be true to say that the US has a high level of ability to intervene, this would only make sense insofar as it is not partnered by states that it cannot realistically be expected to work with, such as Russia.
} 
do with the costs they must bear in the course of doing so' (2001, p. 461). Given this, Miller suggests that we have to ' $[\ldots]$ begin by weighing effectiveness against cost to determine whose capacity is the greatest in the morally relevant sense' (2001, p. 461).

While it might be appropriate to weigh effectiveness against costs in other cases, two reasons speak against it in the context of humanitarian intervention. First, there is the practical point that in order to determine the costs a state would face we must know what that state's contribution is supposed to be. Hence, costs can only play a role once we have an initial idea of what each state is supposed to contribute, as determined by one or more prior principles (such as brute ability). Second, the degree and the intensity of the harm that is to be averted provide reason for prioritising the victims. The costs intervening agents face are undoubtedly relevant, but they should not carry the same weight as effectiveness. ${ }^{15}$ But because costs affect the ability of states to pursue other worthy ends, they still matter. First, costs should matter in an absolute sense by forming a threshold above which the costs are such that intervention becomes supererogatory (Caney 2005b, p. 253; Pattison 2010, p. 198). States that would be excessively burdened by intervening have a sufficient reason to say no. Second, costs should also matter in relative terms by acting as a tie-breaker between agents that are similar with respect to effectiveness, but different when it comes to costs.

In sum, the principle of Ability is an attractive option for undermining states' claims not to intervene. But we should be wary of making it the only criterion. Given that it is exclusively forward-looking it cannot accommodate concerns of historical responsibility or capture the importance of how states' ability to intervene has come about. This indicates that it should be supplemented by other principles. In the next section I will discuss two candidates for this purpose.

\section{Historical Responsibility and Historical Taint}

In this section I will discuss two ways in which historical considerations can serve to complement Ability when answering the duty specification question. The first way in which historical considerations may weigh on states' claims not to intervene is in the sense of historical responsibility. While the concept of historical responsibility has been widely discussed in debates about international burden sharing more generally, ${ }^{16}$ it has been less discussed in relation to humanitarian intervention. ${ }^{17}$ The concept of historical responsibility may be captured by a range of different principles, and the attractiveness of invoking it generally derives from the idea that agents that have caused harm should also be held remedially responsible for rectifying that harm. For example, one might think that, given their role in the second war in Iraq, the US and the UK have a stronger duty to intervene to help

\footnotetext{
15 I believe this holds true at least in cases involving large-scale violations of very important rights. It is possible that more weight should be attached to costs were one to adopt a lower threshold for intervention. Space precludes further discussion of this issue.

16 See for example (Caney 2005a, p. 752, 2010, p. 205; Miller 2001, pp. 455-460; Page 2011, p. 414).

17 Exceptions include Miller (2011, pp. 207-208), Fabre (2012, pp. 189-191), Tan (2006, pp. 97-99) and Hjorthen and Duus-Otterström (2016).
} 
civilians caught in the throes of ISIS, at least prima facie. The idea is captured by the following principle:

Historical Responsibility: If a state (or set of states) is especially responsible for the conditions that call for intervention in another state, then that state (or set of states) has a weaker claim to reject the burden of intervention (cf. Hjorthen and Duus-Otterström 2016, p. 189).

The notion of being 'especially responsible' may take different forms, such as causal responsibility, moral responsibility or outcome responsibility (Miller 2007, pp. 100-103). ${ }^{18}$ Despite their differences they share a common denominator in that they generally require the existence of a causal link. A pertinent example would be a case where a state, through trading arms with a rights-violating regime, has contributed to the occurrence of violence.

I should point out that the focus here is on the historical responsibility of outside states and their contribution to the occurrence of atrocities. This is because the reason the question of humanitarian intervention comes up in the first place is that the home (or target) state has failed (through ill will or incapacity) to prevent the atrocities from happening. This does not deny the responsibility of those actively carrying out the atrocities, such as the authorities of the state where the atrocities take place.

Historical responsibility is limited in scope by the following considerations. First, it can be both difficult and time-consuming to establish causal links, especially in cases involving complex historical processes and multiple agents (see e.g. Pattison 2010, p. 193). Yet, one should not exaggerate this problem. While establishing with sufficient clarity whether and to what extent outside states are relevantly linked to the occurrence of violence may sometimes be difficult, there are presumably cases where we can say, with sufficient certainty, that some states are more responsible than others. For example, there is reason to believe that Belgium, through its colonial rule in Rwanda, exacerbated (or even created) the conflict between the Hutu and the Tutsi that precipitated the 1994 genocide. $^{19}$

Second, historical responsibility only applies in cases where an outside state (or set of states) is in fact historically responsible in the relevant sense. While outside states may have had a hand in many cases where violence has followed, it is conceivable that there are also cases where outside states played no role at all.

Third, it cannot be applied to cases involving what Ed Page (2011, p. 415) refers to as 'disappearing perpetrators'. Specifically, it is unable to account for historical injustices committed by past generations. If one adopts an individualist perspective, according to which the duties of states derive from the duties of its individual citizens, historical responsibility will be unable to point to anyone in cases where those responsible are no longer alive. This limitation is clearly relevant for the case of humanitarian intervention, as the historical genesis of at least some cases of mass

\footnotetext{
${ }^{18}$ I submit that the principle of historical responsibility is most plausible when it relies on moral responsibility. For further discussion of historical responsibility in the context of humanitarian intervention, see Hjorthen and Duus-Otterström (2016).

${ }^{19}$ For empirical accounts of Belgium's role in Rwanda, see e.g. Jones (2007, p. 145) and Wheeler (2000, p. 210).
} 
atrocities is linked to acts of colonialism committed by people that are long since dead.

Historical responsibility is also vulnerable to two objections that are more specific to the case of humanitarian intervention. First, it is far from obvious that states that are historically responsible for the atrocities also have the ability to intervene effectively. We have to ask whether it would make sense to assign the duty to intervene to a country whose military capacity is severely limited. Doing so would risk defeating the purpose of the intervention, which is to save as many lives as possible.

A second objection is that historically responsible states will be especially unsuited to intervene seeing as they might face higher levels of resistance from the local population and might therefore be less effective. Cécile Fabre argues that this gives rise to a paradox in that 'the greater the degree of responsibility for rightsviolations, the weaker the case for assigning the duty to intervene to wrongdoers' (2012, pp. 190-191). ${ }^{20}$ If this objection is sound, there would be little more to say for the role of historical responsibility in this context. Yet, while this objection might sometimes apply, empirical research on this particular question is scarce. It is certainly conceivable that there are cases where the objection does not hold. For instance, it might be that relevant segments of the local population share the intuition mentioned above that historically responsible states should bear the burden of intervention (Hjorthen and Duus-Otterström 2016, p. 191).

So far we have seen that historical responsibility offers the opportunity to take into account the role of outside states in the occurrence of atrocities. By pointing to connections between prospective duty-bearers and the occurrence of atrocities, states' complaints against taking remedial action are undermined, at least prima facie (Hjorthen and Duus-Otterström 2016, pp. 195-196). In this sense it seems that it can help solve a central problem with the principle of Ability, namely that it is completely ahistorical. But we have also seen that there are important limitations in the scope of the principle. Where one or more of the above objections apply, the role of historical responsibility in undermining states' claims not to intervene is at best limited.

But notice that there is a second way in which historical considerations may be invoked. Rather than focusing on contribution to the genesis of violence, this second reading calls into question states' entitlements to their resources by drawing attention to the ways in which their resources have come about (Caney 2006, p. 477). ${ }^{21}$ Using historical conditions in this way relies on what Simon Caney calls the 'Negative view' of how historical processes matter, and the point is to uncover whether states' material capacity for intervention may have been built using resources generated through violating the rights of others. ${ }^{22}$ For example, a state may have built its capacity for intervention based on proceeds from the selling of

\footnotetext{
20 This objection is discussed in more detail in (Hjorthen and Duus-Otterström 2016).

21 For related views, see Duus-Otterström (2014, p. 453), Goodin (2013, p. 487).

22 This can be contrasted with the 'Positive View', whereby ' $[\ldots]$ we start with an originally just state of affairs, then consider the effects of the historic injustice and seek to rearrange things so that the historical injustice is undone' (Caney 2006, p. 477).
} 
arms to corrupt and rights-violating regimes. States whose capacity for intervention has come about in such ways will have their complaints against taking remedial action undermined. The idea is captured by the following principle:

Historical taint: If a state (or set of states) has built its ability to intervene on resources that result from rights-violations, then that state (or set of states) has a weaker claim to reject the burden of intervention.

We may see historical taint as a response to the objection facing the principle of Ability that it is insensitive to how states' ability to intervene has come about. Moreover, seeing as historical taint is object- rather than person-centred-that is, focused on the objects/resources that result from wrongdoing rather than on the wrongdoers - it is not vulnerable to the 'disappearing perpetrators'-objection (see e.g. Goodin 2013, pp. 480-482). Historical taint thus allows us to appeal to the significance of history even in cases where historical responsibility does not apply, such as cases involving intergenerational injustice.

It is worth noting that historical responsibility and historical taint may operate at the same time. For example, selling arms to a genocidal regime can make a state historically responsible, in addition to raising concerns of historical taint (provided the state's capacity for intervention is built on resources that stem from the armstrade). But although historical responsibility and historical taint may focus on the same injustice, this is not necessary.

For historical taint there is no requirement that there be a causal connection between the duty-bearer and the atrocities that motivate the intervention, and in this sense it clearly differs from historical responsibility. Some may perceive this as a weakness. At issue here is whether the tainted capacity and the atrocity must flow from the same injustice, that is, whether they must share a common unjust 'source'. In other words: is it required that the resources used to intervene against mass killing in state A stem from the same injustice that caused the mass killing (e.g. the selling of arms to the authorities of A)? I do not deny that our intuition about taint may be stronger in cases where there is a common source, such as when we say that the resources that go into stopping a war should be gathered from those who have benefitted from the preconditions of that particular war. However, it stands to reason that a state whose capacity for intervention is built on the proceeds of its arms sales to a rights-violating regime will have its claim to these resources undermined regardless of the identity of the regime with which it has been dealing. ${ }^{23}$ Regardless of whether the resources on which the ability is built stem from the same source as the atrocities, tainted resources can undermine a state's claim not to intervene by undermining its claim to some of the resources in its possession. ${ }^{24}$

\footnotetext{
${ }^{23}$ For further discussion about the common source problem, see Duus-Otterström (2016), Parr (2016, pp. 995-996).

24 Obviously, the duty to intervene might come into conflict with obligations of compensation. But even if we allow that obligations to compensate should sometimes take priority over obligations to intervene, this would do little to undermine the relevance of historical taint for the duty to intervene. This is because a large part of most states' resources are likely to be tainted by historical injustices, and only a subset of these will be subject to claims for compensation, and only a subset of these will outweigh the importance of intervention.
} 
It is time to take stock. In this section we have seen that there are two ways in which historical injustices may be used to complement the principle of Ability in undermining the claims of states not to intervene. But we have also seen that there are limitations as to where they apply, albeit more so for historical responsibility than for historical taint. In particular, both principles are vulnerable to the objection that they may point to states that lack the ability to intervene effectively. How, then, should historical responsibility and historical taint be weighed against Ability? This is the topic of the next section.

\section{Combining Ability and Historical Responsibility/Taint}

Given that Ability, historical responsibility and historical taint are widespread and attach to many states, it is important to determine how these factors should be combined.

Consider an example where states $\mathrm{A}$ and $\mathrm{B}$ are equal in terms of ability, but where $\mathrm{A}$ is historically responsible. In such a case we should say that A has the weaker claim not to intervene, and should therefore be assigned a stronger duty to intervene. We do, however, want to avoid the conclusion that historical responsibility can outweigh Ability. In a case where $\mathrm{A}$ is historically responsible, but slightly less able than B, we do not want to say that it is A that has the weakest claim not to intervene (this is consistent with saying that A has other remedial duties or duties of compensation). Due to the importance of saving lives, effectiveness should not be traded off in the case of humanitarian intervention. Historical responsibility should therefore be used to undermine states' claims not to intervene if, and only if, having historically responsible states performing the intervention would not negatively affect the protection of the victims. The same goes a fortiori for historical taint. ${ }^{25}$

Still, one might think that historically responsible states can be required to bear greater costs, and can therefore be asked to contribute in ways that for nonresponsible states would be supererogatory. However, this idea is more plausible if historical responsibility is seen as a matter of rectificatory justice. On the entitlement undermining view that I adopt the idea has rather less purchase, seeing as no special weight is assigned to the idea of responsible states making up for past wrongdoing. Instead I propose that the role of historical responsibility and historical taint is to act as tie-breakers.

Some might object that using historical responsibility/taint only in the capacity of tie-breakers reduces them to irrelevance. After all, it sounds quite unlikely that any two states would be exactly tied when it comes to their ability to intervene. Despite this, the charge of irrelevance is mistaken. In order to show this, I must specify what I mean by states being equally able, and hence what it is that characterises a tie. A tie in terms of ability should be understood as a situation where

\footnotetext{
${ }^{25}$ Questions might arise as to whether these factors should be weighed differently for interventions aimed at halting violations of non-basic rights. Discussion of this important issue must be deferred to a future occasion.
} 
the difference between two or more states is such that choosing one state rather than another would not make a difference for the victims, measured in protection of basic human rights. In other words, the states can make a similar contribution without this compromising the overall effectiveness of the intervention. We might call this a functional tie to keep this idea distinct. To illustrate, consider a case where states (A, ..., E) have been picked out as the most able to undertake an intervention. D is historically responsible for the case at hand. $(\mathrm{A}, \ldots, \mathrm{E})$ differ in ability in descending order, and $\mathrm{C}$ therefore has a higher score on factors that bear on ability to intervene than D. However, C's 'extra' ability is such that it is of no benefit to the victims, and is therefore irrelevant. D's ability is fully satisfactory in order to make the contribution originally assigned to $\mathrm{C}$. Thus, $\mathrm{C}$ and D are sufficiently similar to make this pair a functional tie. This only applies in cases where the states concerned are not required to 'max out' their capacity, but it seems to me that there may well be many such cases. Hence, even if historical responsibility/taint is only a tie-breaker, it can have a considerable impact on how the duty to intervene is assigned. The same argument can be made with respect to costs. For states that are functionally tied, the costs they would face in protecting the victims can act as a tie-breaker.

Naturally, this raises the question of how costs, historical responsibility, and historical taint should be weighed relative to each other. They all come in degrees and it is not obvious that any one of them should have lexical priority. It seems, therefore, that their relative weights should be determined case-by-case. If the costs are such that they have a severe impact on welfare, it might be that it (costs) can outweigh historical responsibility and/or taint. On the other hand, it seems implausible that small changes in welfare can outweigh the importance of historical responsibility and taint. When it comes to the relationship between historical responsibility and historical taint the fact that historical responsibility appeals to a common 'source' for historical injustice and atrocity speaks in favour of giving more weight to historical responsibility. However, given the wide range of historical injustices that may have tainted states' capacity for intervention, it is likely that historical taint will closely track ability and attach to many (or even most) states. It is therefore likely that historical responsibility will apply in addition to, rather than in competition with, historical taint.

In sum, while the principle of Ability is the most important factor for undermining states' claims not to intervene, historical responsibility and historical taint will often steer the distribution since many states can be presumed to be functionally tied in their ability to put an effective end to the violence.

\section{Distributive Fairness}

One of the main critiques I raised against Pattison's account was that assigning the duty to intervene only to the most legitimate agent has unfair distributive implications. Moreover, distributive unfairness provides a (defeasible) reason for states to reject the burden of intervention. It is important, therefore, to highlight how my account can accommodate distributive fairness among the group of potential interveners. 
Ability, historical responsibility and historical taint all come in degrees and are moreover differentially distributed among states. Fairness requires that we take this into account. The history-sensitive ability-account incorporates this insight. It suggests that the duty to intervene should be assigned in inverse proportion to the strength of states' claims not to intervene, and that states' claims not to intervene should be determined by states' 'scores' on ability, adjusted for costs, historical responsibility and historical taint. Hence, my view suggests that a state that is twice as able as another should, ceteris paribus, take on twice the burden.

The focus on proportionality is, I would argue, not only inherent in the factors themselves (Ability, historical responsibility, historical taint), but can also be derived from a familiar account of fairness. John Broome suggests that '[...] fairness is concerned only with how well each person's claim is satisfied compared with how well other people's are satisfied', and that fairness requires that 'claims should be satisfied in proportion to their strength' (1990, p. 95 [emphasis in original]). Broome's account can be applied here by saying that states have defeasible claims not to intervene (that is, to reject the burden of intervention) that should be satisfied in proportion to their strength, as determined by Ability, historical responsibility and historical taint, in line with what was described above. $^{26}$

The emphasis on distributive fairness speaks in favour of my account for three main reasons: first, fairness is important in itself. Second, fair burden-sharing has instrumental importance in that it can help alleviate the undersupply of intervention. Having more states share in the burden of intervention will lower the costs each state faces, and thus removes an important disincentive for prospective interveners. $^{27}$ Third, empirical research indicates that increased diversity in missions contributes to increased effectiveness (Bove and Ruggeri 2016). In sum, fair burden-sharing is not only morally important in itself, but also instrumentally valuable given the goal of saving the victims. In other words, if we care about effective intervention, we should also care about distributive fairness among potential interveners.

Given its focus on proportionality, my account might face the objection that it impracticable. This is because it seems that distributing the duty to intervene in proportion to states' claims not to intervene would assign the duty to a very large number of states. The objection is that this would not work due to the operational problems that tend to arise when a significant number of states work together in military operations. Hence, distributing the burden among a large number of states might be detrimental to the prospects for success.

But note that this objection builds on a misunderstanding of what my account entails. While it is probably true that having too many states take part in the intervention would be bad, this is not a problem for my account. This is due to the fact that the burden that my account seeks to distribute is defined on the basis of

\footnotetext{
${ }^{26}$ For discussion of whether there is sometimes a duty to do more than one's fair share, see e.g. Hohl and Roser (2011), Stemplowska (2016).

27 The view that undersupply is a real problem finds support in 'The People on War Report' (ICRC 1999, pp. 74-79).
} 
what it takes to realise the goal of saving the victims effectively. Far from suggesting that the duty to intervene should be distributed proportionally among all states that have some degree of the relevant properties (such as Ability), proportionality should be interpreted to mean proportionality among as many states as possible without compromising mission effectiveness. This is because the goal of saving the victims is ultimately of paramount importance.

Someone might object that, while my account is right to focus on distributive fairness, the focus on proportionality should be substituted by a scheme whereby states alternate from time to time in taking on the burdens of intervention. It might be argued that this would be equally fair, more feasible, and good for international cooperation. However, while such a scheme of diachronic fairness would be an improvement over the status quo, the proposal should be rejected for the following reasons: first, given that humanitarian interventions are rare events, it would likely take a very long time to achieve a fair outcome. It is unlikely that diachronic fairness could be achieved within a single generation. Second, states may not trust other states to take on their fair share in the future, and this might make them less inclined to pick up the cost in the present. Third, given the rather static distribution of capacity for intervention among states, it is not clear that different interveners can be chosen on each occasion without compromising the effectiveness of interventions.

Summing up, the message of the history-sensitive ability-account is that the duty to intervene should be assigned in inverse proportion to states' claims not to intervene. This is primarily determined by ability to intervene, and for reasons of distributive fairness we should prefer interventions that have more contributing states, up to the point where the overall effectiveness of the intervention would be harmed by adding further actors. Where states are functionally tied, costs, historical responsibility and historical taint act as tie-breakers.

Finally, it should be pointed out that there is more to humanitarian intervention than the task of prosecuting the war. Several theorists have alluded to the point that we can accommodate concerns of fairness by having some states undertake the intervention while others contribute in other ways, such as by providing funding and material resources (Fabre 2012, pp. 190-191; Pattison 2010, pp. 197-198). Such solutions would go some way towards alleviating any remaining concerns we may have about distributive fairness, but I cannot develop this part of the overall picture here.

\section{Conclusion}

In this paper I have examined how the duty to undertake humanitarian intervention should be assigned to particular states. I have argued that a plausible answer to the question of who should intervene should be sensitive to states' ability to save the victims, historical responsibility and distributive fairness among the duty-bearers. Against this background I proposed that the duty to undertake humanitarian intervention should be assigned to states in inverse proportion to their claim not to intervene, as determined by ability to intervene, costs, historical responsibility and 
historical taint. However, costs and historical concerns should play a role only when it would not compromise the effectiveness of interventions. The account provides a morally attractive answer to how the duty to intervene should be assigned, and avoids the counterintuitive implications of Pattison's account.

Acknowledgements Previous drafts of this article were presented at the Nordic Network in Political Theory, Oslo (November 2016), and at the Oslo-Gothenburg workshop in political theory, Gothenburg (June 2016). I gratefully acknowledge the helpful and constructive comments I received from the participants at these events. Special thanks go to my discussants at these events, Tor Otterholt and Anders Herlitz who provided extensive and helpful comments. Special thanks also go to an anonymous reviewer, Kim Angell, Johan Karlsson Schaffer, Robert Huseby, James Pattison, Göran Duus-Otterström and Henrik Friberg-Fernros, who have all provided invaluable comments along the way.

Open Access This article is distributed under the terms of the Creative Commons Attribution 4.0 International License (http://creativecommons.org/licenses/by/4.0/), which permits unrestricted use, distribution, and reproduction in any medium, provided you give appropriate credit to the original author(s) and the source, provide a link to the Creative Commons license, and indicate if changes were made.

\section{References}

Baer, Daniel. 2011. The Ultimate Sacrifice and the Ethics Of Humanitarian Intervention. Review of International Studies 37(1): 301-326.

Bagnoli, Carla. 2006. Humanitarian Intervention as a Perfect Duty: A Kantian Argument. In Nomos XLVII: Humanitarian Intervention, ed. Terry Nardin and Melissa S. Williams, 117-142. New York: New York University Press.

Bove, Vincenzo, and Andrea Ruggeri. 2016. Kinds of Blue: Diversity in UN Peacekeeping Missions and Civilian Protection. British Journal of Political Science 46(3): 681-700.

Broome, John. 1990. Fairness. Proceedings of the Aristotelian Society 91: 87-101.

Buchanan, A. 1999. The Internal Legitimacy of Humanitarian Intervention. Journal of Political Philosophy 7(1): 71-87.

Buchanan, Allen. 2000. Justice, Legitimacy, and Human Rights. In The Idea of a Political Liberalism: Essays on Rawls, ed. Victoria Davion and Clark Wolf, 73-99. Oxford: Rowman and Littlefield.

Caney, Simon. 2005a. Cosmopolitan Justice, Responsibility, and Global Climate Change. Leiden Journal of International Law 18(4): 747-775.

Caney, Simon. 2005b. Justice Beyond Borders: A Global Political Theory. Oxford: Oxford University Press.

Caney, Simon. 2006. Environmental Degradation, Reparations, and the Moral Significance of History. Journal of Social Philosophy 37(3): 464-482.

Caney, Simon. 2010. Climate Change and the Duties of the Advantaged. Critical Review of International Social and Political Philosophy 13(1): 203-228.

Duus-Otterström, Göran. 2014. The Problem of Past Emissions and Intergenerational Debts. Critical Review of International Social and Political Philosophy 17(4): 448-469.

Duus-Otterström, Göran. 2016. Benefiting from Injustice and the Common-Source Problem. Institute for Futures Studies, Working paper 2016:4, Available at: http://www.iffs.se/publikationer/ arbetsrapporter/benefiting-from-injustice-and-the-common-source-problem/.

Estlund, David. 2011. Human Nature and the Limits (If Any) of Political Philosophy. Philosophy and Public Affairs 39(3): 207-237.

Evans, Gareth J. 2008. The Responsibility to Protect: Ending Mass Atrocity Crimes Once and for All. Washington, DC: Brookings Institution Press.

Fabre, Cécile. 2012. Cosmopolitan War. Oxford: Oxford University Press.

Gizelis, Theodora-Ismene, and Kristin E. Kosek. 2005. Why Humanitarian Interventions Succeed or Fail: The Role of Local Participation. Cooperation and Conflict 40(4): 363-383. 
Goodin, Robert E. 2013. Disgorging the Fruits of Historical Wrongdoing. American Political Science Review 107(3): 478-491.

Gross, Michael L. 2008. Is There a Duty to Die for Humanity?: Humanitarian Intervention, Military Service and Political Obligation. Public Affairs Quarterly 22(3): 213-229.

Haydar, Bashshar. 2009. Special Responsibility and the Appeal to Cost. Journal of Political Philosophy 17(2): 129-145.

Hjorthen, Fredrik D. 2017. Who Should Pay for Humanitarian Intervention? European Journal of Political Theory, 0(0), 1-20 (epub ahead of print).

Hjorthen, Fredrik D., and Göran Duus-Otterström. 2016. Humanitarian Intervention and Historical Responsibility. Journal of Global Ethics 12(2): 187-203.

Hohl, Sabine, and Dominic Roser. 2011. Stepping in for the Polluters? Climate Justice under Partial Compliance. Analyse and Kritik 33(2): 477-500.

ICRC. (1999). The People on War Report. Retrieved from https:/www.icrc.org/eng/assets/files/other/ icrc_002_0758.pdf. Accessed 4 February 2016.

Jones, Bruce D. 2007. Rwanda. In United Nations Interventionism 1991-2004, ed. Mats Berdal, and Spyros Economides, 139-167. Cambridge: Cambridge University Press.

Krain, Matthew. 2005. International Intervention and the Severity of Genocides and Politicides. International Studies Quarterly 49(3): 363-388.

McMahan, Jeff. 2010. Humanitarian Intervention, Consent, and Proportionality. In Ethics and Humanity Themes from the Philosophy of Jonathan Glover, ed. N. Ann Davis, Richard Keshen and Jeff McMahan, 44-72. Oxford: Oxford University Press.

Miller, David. 2001. Distributing Responsibilities. The Journal of Political Philosophy 9(4): 453-471.

Miller, David. 2007. National Responsibility and Global Justice. Oxford: Oxford University Press.

Miller, David. 2011. Humanitarian Intervention and the Responsibility to Protect: Who Should Intervene? By James Pattison. Global Discourse: An Interdisciplinary Journal of Current Affairs and Applied Contemporary Thought 2(1): 205-208.

Page, Edward A. 2011. Climatic Justice and the Fair Distribution of Atmospheric Burdens: A Conjunctive Account. The Monist 94(3): 412-432.

Parr, Tom. 2016. The Moral Taintedness of Benefiting from Injustice. Ethical Theory and Moral Practice 19(4): 985-997.

Pattison, James. 2010. Humanitarian Intervention and the Responsibility to Protect: Who Should Intervene? Oxford: Oxford University Press.

Pattison, James. 2011. The Rights and Duties of Humanitarian Intervention: Who Should Intervene? A Reply to Two Critics. Global Discourse: An Interdisciplinary Journal of Current Affairs and Applied Contemporary Thought 2(1): 213-217.

Pattison, James. 2013. Is There a Duty to Intervene? Intervention and the Responsibility to Protect. Philosophy Compass 8(6): 570-579.

Pattison, James. 2015. Mapping the Responsibilities to Protect: A Typology of International Duties. Global Responsibility to Protect 7(2): 190-210.

Scheffler, Samuel. 1997. Relationships and Responsibilities. Philosophy and Public Affairs 26(3): 189-209.

Seybolt, Taylor B. 2007. Humanitarian Military Intervention: The Conditions for Success and Failure. Oxford: Oxford University Press.

Stemplowska, Zofia. 2016. Doing More Than One's Fair Share. Critical Review of International social and political philosophy 19(5): 591-608.

Tan, Kok-Chor. 2006. The Duty to Protect. In Nomos XLVII: Humanitarian Intervention, ed. Terry Nardin and Melissa S. Williams, 84-116. New York: New York University Press.

Tesón, Fernando R. 2005. Humanitarian Intervention: An Inquiry into Law and Morality. Ardsley: Transnational Publishers.

Tesón, Fernando R. 2014. The Moral Basis of Armed Humanitarian Intervention Revisited. In The Ethics of Armed Humanitarian Intervention, ed. Don E. Scheid, 61-77. Cambridge: Cambridge University Press.

Wheeler, Nicholas J. 2000. Saving Strangers: Humanitarian Intervention in International Society. Oxford: Oxford University Press.

Vik, Cathinka. 2015. Moral Responsibility, Statecraft and Humanitarian Intervention: The US Response to Rwanda, Darfur, and Libya. Abingdon: Routledge. 